\title{
Preliminary Tests Regarding Fumigant Effect of Volatile Oils Obtained from Medicinal Plants
}

\author{
Cătălina STAN (TUDORA) ${ }^{12}$, Adriana MUSCALU ${ }^{2}$, Ana Cristina FĂTU ${ }^{3}$, Mihaela Monica DINU ${ }^{3}$, \\ Florentina ISRAEL-ROMING ${ }^{1}$ \\ ${ }^{1}$ University of Agronomic Sciences and Veterinary Medicine of Bucharest, 59 Marasti Blvd, Bucharest, \\ Romania \\ ${ }^{2}$ National Institute of Research-Development for Machines and Installations Designed to Agriculture and \\ Food Industry-INMA, 6 Ion Ionescu de la Brad Avenue, Bucharest, Romania \\ ${ }^{3}$ Research and Development Institute of Plant Protection - ICDPP, 8 Ion Ionescu de la Brad Avenue, \\ Bucharest, Romania \\ *corresponding author: cmc_tudora@yahoo.com
}

Bulletin UASVM Animal Science and Biotechnologies 76(1)/ 2019

Print ISSN 1843-5262; Electronic ISSN 1843-536X

DOI:10.15835/buasvmcn-asb: 2018.0023

\begin{abstract}
The objective of this work was testing 4 volatile oils obtained from new varieties of medicinal plants (yellow basil; red basil; marigold; hyssop), over Beauveria brongniartii (BbgMm1a/09) entomopathogenic fungi and Sitophilus granarius, deposit insect. The results obtained showed that at different concentrations, red basil volatile oil showed the strongest inhibitory effect compared to the other tested oils (yellow basil, marigold and hyssop). Concerning the insecticidal action, the preliminary tests with the 4 volatile oils obtained from new varieties of medicinal plants had no effect on the test insect - Sitophilus granarius.
\end{abstract}

Keywords: Beauveria brogniartii, fumigant, Sitophilus granarius

\section{Introduction}

Medicinal plants are an important source of useful compounds that can be used directly or can serve as precursors for the production of agents that can be used as potential controllers of disease and pest, insects, etc. (Planta Europa, 2010). The antimicrobial effect of extracts obtained from medicinal plants (Zarkani et al., 2016), has also been studied on gram-positive and gram-negative bacteria (Semnani et al., 2017).

Stored grain infestation is a very serious problem causing economic damage by deterioration of the quality of food grains and food products. The granary weevil, Sitophilus granarius is a major pest of stored grain capable of causing considerable loses (Rosca et al., 2009). Among alternatives to chemical treatments against store insect pests, the biological control using pathogens or natural plant products have shown promising results. Essential oils have shown insecticidal activity against field crop pests (Verma et al., 2000). Among the pathogens, the entomopathogenic fungi have been most studied for stored product insect control (Kavallieratos et al., 2006; Athanassiou and Steenberg, 2007; Kavallieratos et al., 2008; Golnaz et al., 2011). Isolates of entomopathogenic fungus Beauveria sp. were found to be pathogenic against S. granaries (Storm et al., 2016). The hypothesis of simultaneously using the essential oils and entomopathogenic fungus treatments against S. granarius lead us to test the fumigant effect 
of essential oils on the insect pests and mycelial growth of $B$. brongniartii.

\section{Materials and methods}

Determination of antifungal effects of the volatile oils on mycelial growth - the antifungal properties of volatile oils were evaluated for assessing its fumigant phase effects towards mycelial growth of $B$. brongniartii. For this, agarmycelium plugs $(7 \mathrm{~mm}$ diameter) were cut from the edge of a colony of $B$. brongniartii after 5 days of growth on solid media. Using a microbiological loop, each cut piece was transferred to the center of a Petri plate $(90 \times 15 \mathrm{~mm})$ containing PDA medium $(\sim 15 \mathrm{ml} /$ plate $)$. A sterile filter paper disc (5mm diameter, Filtrack 388) was glued to the inside of the Petri plate lid and was impregnated with volatile oil to obtain final concentrations of 1 , 2, 5, 10, 20, 50 and $100 \mu \mathrm{ll}^{-1}$ air. Immediately after the volatile oil application, the boxes were sealed with parafilm and incubated at $23^{\circ} \mathrm{C}$. A cuvette of water was placed in the incubator. The dilution of the oil to obtain concentrations of 1 and $2 \mu \mathrm{l} \mathrm{l}^{-1}$ air was achieved by dissolving the required amount of oil in warm water-agar sterile solution $(0.2 \%)$. Each concentration was tested in 3 repetitions. The size of the colonies was measured in two perpendicular directions for 7 days. The inhibition of mycelium growth was based on the size of the control colony using the formula: mycelial growth inhibition MGI $(\%)=(($ Dc-Ds $) / D c) * 100$, where $\mathrm{Dc}(\mathrm{mm})=$ control colony diameter and Ds $(\mathrm{mm})=$ sample colony diameter.

Determination of insecticidal effects of the volatile oils on $S$. granarius insect - the Granary weevil adultscultured at the Research Development Institute for Plant Protection, Romania, were used in this study. This culture was kept in darkness at room temperature $\left(22 \pm 2^{\circ} \mathrm{C}\right)$. Round filter papers (6 $\mathrm{cm}$ diameter) were impregnated with $10 \mu \mathrm{l}$ of volatile oil and placed at the bottom of a $250 \mathrm{ml}$ Berzelius glass in which 100 grams of wheat grains were added over which 30 adult insects were released. The Berzelius glasses were immediately placed in $5 \mathrm{~L}$ glass jars and immediately capped. The treatments were tested in the dark at $20^{\circ} \mathrm{C}$ and $55 \%$ relative humidity. The control treatments did not include volatile oils. The number of dead $S$. granarius adults was determined at 2, 4 and 7 days after the initiation of the treatment.
Statistical analysis - The effects of volatile oil treatments and concentrations on mycelium growth and the interaction between these factors were analyzed using the two-way ANOVA followed by Bonferroni post-hoc test ( $\mathrm{P} \leq 0.05)$. Statistical data interpretation was performed using the GraphPadPrism5 software.

\section{Results and discussions}

The four volatile oils tested showed a strong fungistatic effect $(100 \%)$ at the concentration of $100 \mu \mathrm{l} / \mathrm{l}$ air two days after inoculation and for basil oils (yellow and red) this effect was maintained at the same level even after 7 days (Figure1). It is also noted that in the first two days, all oils in concentrations of 1 and $2 \mu \mathrm{l} \mathrm{l}^{-1}$ air have a mycelium growth stimulating effect. The inhibitory effect is positively correlated with the tested concentration of all oils. The two-way ANOVA test showed that treatment factors $(\mathrm{df}=3, \mathrm{~F}=10.76, \mathrm{p}=0.003)$ and concentrations $(\mathrm{df}=6, \mathrm{~F}=198.1, \mathrm{p}<0.0001)$ showed a highly significant influence on mycelium growth. At the concentration of $5 \mu \mathrm{l} / \mathrm{l}$ air, the inhibition percentage caused by the volatile action of red basil oil is significantly higher than that of yellow basil oil $(\mathrm{p}<0.05)$ and hyssop $(\mathrm{p}<0.05)$. At the concentration of 10 and $20 \mu \mathrm{l} / \mathrm{l}$ of air, there are no statistically significant differences between mycelium inhibition percentages. At $50 \mu \mathrm{l} / \mathrm{l}$ air, there are significant differences between the yellow basil and marigold treatments $(p<0.05)$. Also, the inhibition percentage due to the volatile action of red basil oil on fungal mycelium is very significant compared to that of marigold and hyssop oils $(\mathrm{p}<0.01)$. At the concentration of 100 $\mu \mathrm{l} / \mathrm{l}$ air there are insignificant differences between the treatments with yellow basil, red basil, and hyssop. Compared to these treatments, the marigold oil had the weakest effect of inhibiting the mycelium growth, the difference being very significant.

Studies on the compatibility of essential oils extracted from natural product commonly used in disease management reported various effects on spore germination and growth of Beauveria $s p$. (Mohan et al., 2007; Islam et al., 2010).

No volatile oil produced satisfactory fumigant activity on the adult granary weevils since no mortality was recorded during testing period. This could be related to the low concentration of oil in the air and to the low temperature of incubation. 
(a)

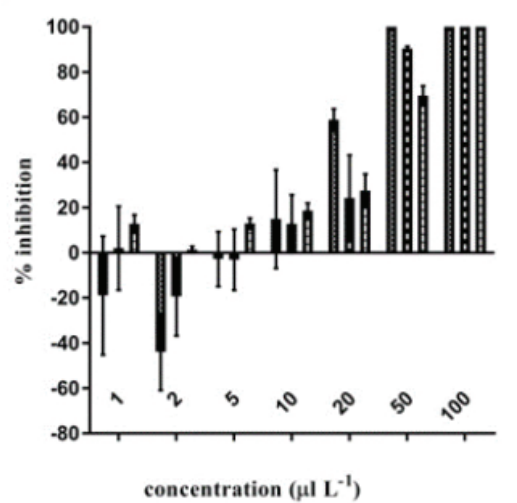

(b)
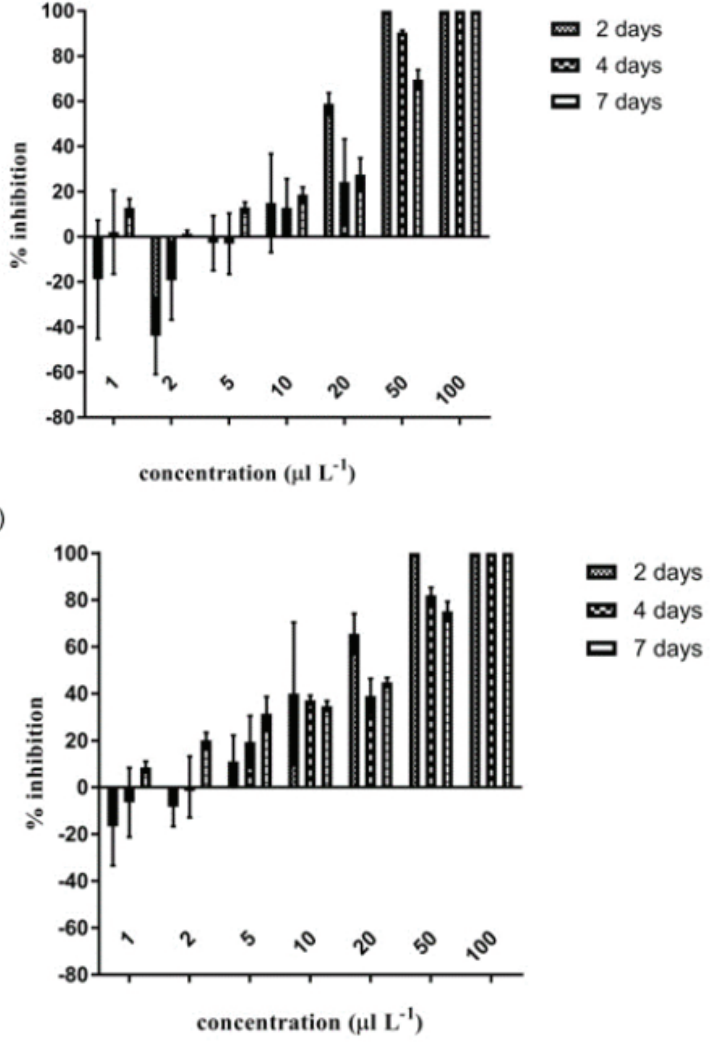

(c)

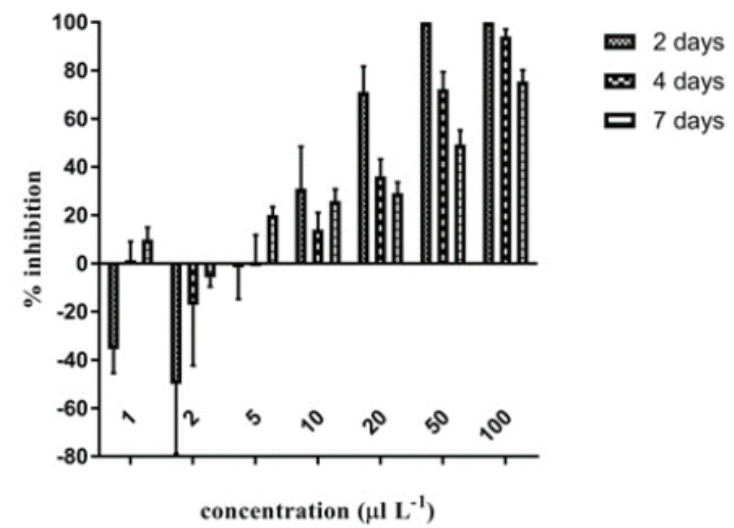

(d)

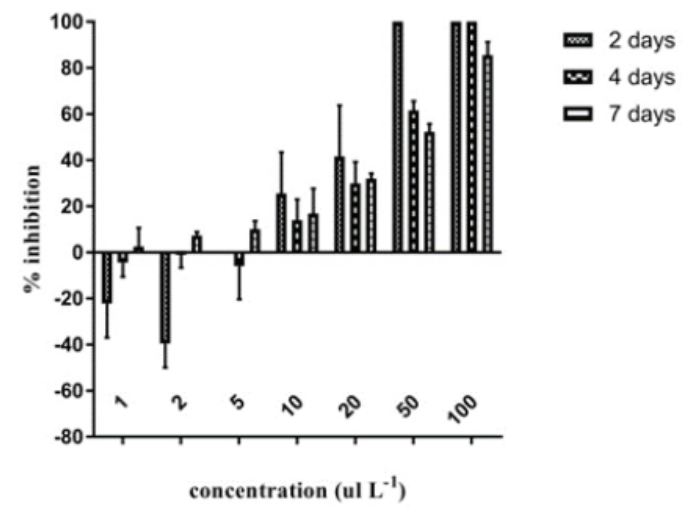

Figure 1. The fumigant effect of Yellow basil (a), Red basil (b), Marigold (c) and Hyssop (d) volatile oils on the mycelial growth of Beauveria brongniartii, at different concentrations, after 2, 4 and 7 days

Laznik et al. (2012) observed an increased fumigant toxicity of different essential oils against adult granary weevils with temperatures. In the experiment, the efficacy of the essential oils at $40^{\circ} \mathrm{C}$ was $95 \%$, whereas their efficacy was considerably lower at lower temperatures (from 12 to $36 \%$ ).

\section{Conclusions}

The growth of fungal mycelium was completely inhibited by volatile basil oils tested at the concentration of $100 \mu \mathrm{ll}^{-1}$ air. At different concentrations, volatile red basil oil showed the most potent inhibitory effect compared to the other oils tested. Concerning the insecticidal action, the preliminary tests with the 4 volatile oils obtained from new varieties of medicinal plants had no effect on the test insect, $S$. granarius. Other values of oil concentration and temperature of incubation should be tested against the pest insect to evaluate the fumigant effect. The results of this study demonstrate the potential of combining two biological control methods, based on essential oils and entomopathogenic fungi products as an alternative to the use of fungicides in disease management.

Acknowledgments. This work was supported by one founding source the NUCLEU Program, carried out with the support of ANCSI, Project no. PN 18300203 "Technology for the establishment and superior utilization of herbal raw material obtained from medicinal plants".

\section{References}

1. Athanassiou CG, Steenberg T (2007). Insecticidal effect of Beauveria bassiana (Balsamo) Vuillemin (Ascomycota: Hypocreales) in combination with three diatomaceous earth formulations againstSitophilus granarius (L.) (Coleoptera: Curculionidae). BiolControl, 40: 411-416

2. Golnaz S, MS Hassan, Imani S, Shojai M, Aramideh $S$ (2011). A laboratory assessment of the potential of the entomopathogenic fungi Beauveria bassiana (Beauvarin) to control Callosobruchus maculates (F.) (Coleoptera: Bruchidae) and Sitophilus granarius (L.) (Coleoptera: Curculionidae). African J Microbiology Res. 5(10): 11921196.

3. Islam M, Olleka A, Ren S (2010). Influence of neem on susceptibility of Beauveria bassiana and investigation of their combined efficacy against sweet potato whitefly, 
Bemisia tabaci on eggplant. Pesticide Biochemistry and Physiology, 98: 45-49.

4. Kavallieratos NG, Athanassiou CG, Michalaki MP, Batta YA, Rigatos HA, Pashalidou FG, Balotis GN, Tomanovic Z, Vayias BJ (2006). Effect of the combined use of Metarhizium anisopliae (Metschinkoff) Sorokin and diatomaceous earth for the control of three stored-product beetle species. Crop Prot, 25: 1087-1094

5. Kavallieratos, NG, Wakefield ME, Athanassiou CG (2008) Factors affecting the attachment of conidia of Metarhizium anisopliae (Metschnikoff) Sorokin (Deuteromycotina: Hyphomycetes) to different body parts of Tribolium confusum Jacquelin du Val (Coleoptera: Tenebrionidae) adults. IOBC/WPRS Bull, 40: 181-190

6. Mohan MC, Reddy NP, Devi UK, Kongara R, Sharma HC (2007). Growth and insect assays of Beauveria bassiana with neem to test their compatibility and synergism, Biocontrol Science and Technology, 17(10):1059-1069.

7. Planta Europa. (2010). http://www.plantaeuropa.org/ pe-EPCS-hot issues-MAP.htm
8. Rosca I, Istrate $\mathrm{R}$ (2009). Tratat de entomologie (agricultura, horticultura, silvicultura), Ed. Alpha MDN, Bucuresti, 471-475.

9. Semnani SN, Hajizadeh N, Alizadeh H (2017). Antibacterial effects of aqueous and organic quince leaf extracts on gram-positive and gram-negative bacteria. Banats J. Biotechnol, 8(16): 54-61.

10. Storm C, Scoates F, Nunn A, Potin O, Dillon A (2016). Improving efficacy of Beauveria bassiana against stored grain beetles with a synergistic co-formulant. Insects, 7(3): 42.

11. Verma N, Tripathi AK, Prajapati V, Bahl JR, Khanuja SPS, Kumar S (2000). Toxicity of essential oil from Lippia albatowards stored grain insects. J.Medicinal and Aromatic Plant Sci., 22(1): 50-54.

12. Zarkani AA (2016). Antimicrobial activity of Hibiscus sabdariffa and Sesbania grandiflora extracts against some G-ve and G+ve strains. Banats J Biotechnol, 7(13): 17-23. 